\title{
微小血管の側々吻合の基礎的検討および臨床応用
}

\author{
池田 公·渋谷 正人·岡田 知久 ·景山 直樹
}

\section{Microvascular Side-to-side Anastomosis}

Basic Problems and Clinical Applications

\author{
Akira Ikeda, Masato Shibuya, Tomohisa Okada and Naoki Kageyama \\ Department of Neurosurgery, Nagoya University, Nagoya
}

\begin{abstract}
Side-to-side anastomosis is rarely performed by neurosurgeons, and the best conditions for microvascular side-to-side anastomosis are still unknown. To discover which conditions maximize blood flow through the anastomosis, side-to-side anastomosis between bilateral common carotid arteries was studied in 25 rats. The results were that the anastomotic orifice should be larger than twice the vessel diameter, and that the anterior wall should be sutured interruptedly. As clinical applications for side-to-side anastomosis, revascularization of the anterior cerebral artery (ACA) using inter-ACA anastomosis was performed in two patients with excellent results.
\end{abstract}

Key words: cerebral revascularization, anterior cerebral artery, side-to-side anastomosis, suture

\section{I はじめに}

直径 1〜2 $\mathrm{mm}$ の微小血管の血行再建術は脳神経外科領 域においてすでに20年近くの歴史があり，数多くの手術が なされている。その多くは浅側頡一中大脳動脈(以下 STA-MCA) 吻合, 媛頭一後下小䏚動脈吻合，またはvein graft t用いた端側吻合で，基璴的検討も多くなされてお り，吻合の技術はほほ確立されたものと思われる，一方， 側々吻合は臨床応用上して左右前大脳動脈間4,6), 後大脳 一上小脳動脈閒13!などが考えられるが，まだ拝例も少な く，基礎的㛟討もなされておらず，いかなる吻合力法が開 存率が良く，また吻合部を介しての血流が良好であるのか 判っていない，直徍 $1 \sim 2 \mathrm{~mm}$ の血管吻合のモデルとして ラットの総钼動脈は適当な大きさであり, 今回我々はこの 血管を用いて側々吻合を行い，適切な吻合口の大きさ，前 壁縫合の方法(結節縫合とするか，連続縫合が良いのか)の 2 点につき調べた。

\section{II 実験}

\section{1. 万法 (Fig. 1)}

25匹の Wistar rat (体重 $250 \sim 300 \mathrm{~g}$ ) 莸 barbiturate 腹腔内 投与にて麻酔し，自然呼吸を行わせ，頸部伸展して固定 する，前頸部に縦切開を加え，可及的に言く総頸動脈を剥 離し，さらに気管前筋群を切断し，上下方向に翻転する。 血管吻合部の外膜を除去したのち，2個の血流遮断用クリ ップを用いて左右の総钼動脈を気管の前で数 $\mathrm{mm}$ にわた り正中に奇せた状態で固定する。これらのラットを2群に 分け，15匹の第 1 群は吻合口の至適な大きさを求めるため に用い，10匹の第 2 群は前壁縫合の適切な方法を求めるた めに用いた。

まず，第 1 群の15匹のラットを以下のごとくさらに 3 群 に分けた。 A 群 $(4$ 匹)は正中笴りに設けた両側総頝動脈の 縦切開(吻合口)の大きさを血管径の䄪 1 倍, B 群(7匹)は それを約 2 倍、 $\mathrm{C}$ 群(4匹)は約 3 倍とした。血管内腔をへ

Address reprint requests to: A. Ikeda, M.D., Department of Neurosurgery, Tokai University, Bohseidai, Isehara, Kanagawa 259-11.

受稿 1984年10月29日受理 1986年2月27日 

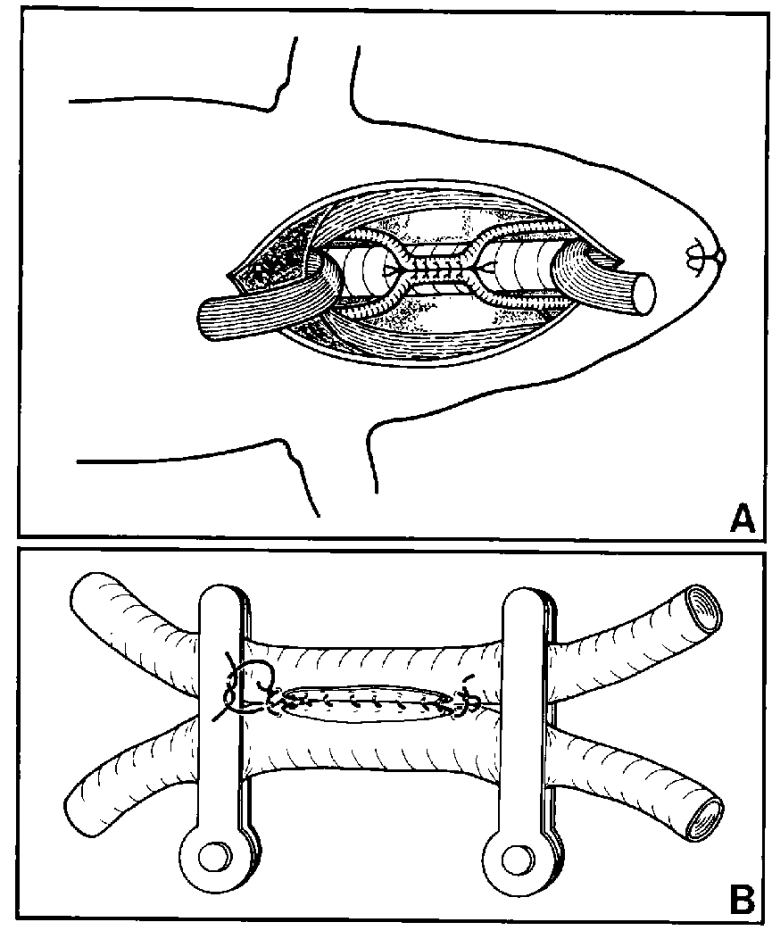

Fig. 1 Illustrations of the experiment. A: Completion of the side-to-side anastomosis using interrupted sutures in the anterior wall. B: Suturing technique.

パリン加生食水で洗潄し，10-0 monofilament nylon 系 (Ethicon 2850)で2本の corner suture 老設ける。ついで Fig. 1Bのごとく, corner sutureに用いた释命系用いて 後壁を血管內腔側より連続縫合する。このとき，縫合采の 締め具合と血管壁が血管内腔にまくれ込まないことに留意 する，その後，前壁をやはり corner sutureに用いた縫合 系をそのまま用いて連続縫合する．Declamp 後の leakagc は通常少ない，次に，前壁縫合には連緮縫命が息いのか， または結節縫合が良いのかを判定するために第2 群に扔い て同様の操作を加え, 吻合口の大きさを血管径の 2 倍上

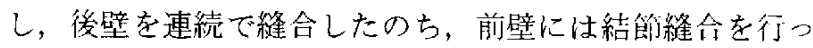

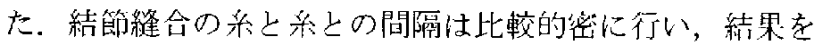
第 1 群の B 群( 血管径の 2 倍の物合口, 前壁怯連続縫合) と比較した。

吻合完了後，近位総頸動脈の一側に血流逶断クリップを かけたのち，電磁血流計(日本光電 MFD-1100，probe size $1.0 \mathrm{~mm}$ ) 雨側末梢側の総頸動脈に装着し，血流量を計測 寸る．Probeの当て方，血压などにより計測值は大きく变 化するため，数回の計測の平均值をとり，一側の血流量が 他側の70\%以下の上き，血流量に左右差ありと判定した。 ラットは術後 1 週から 2 力月の間に sacrifice し, その開存

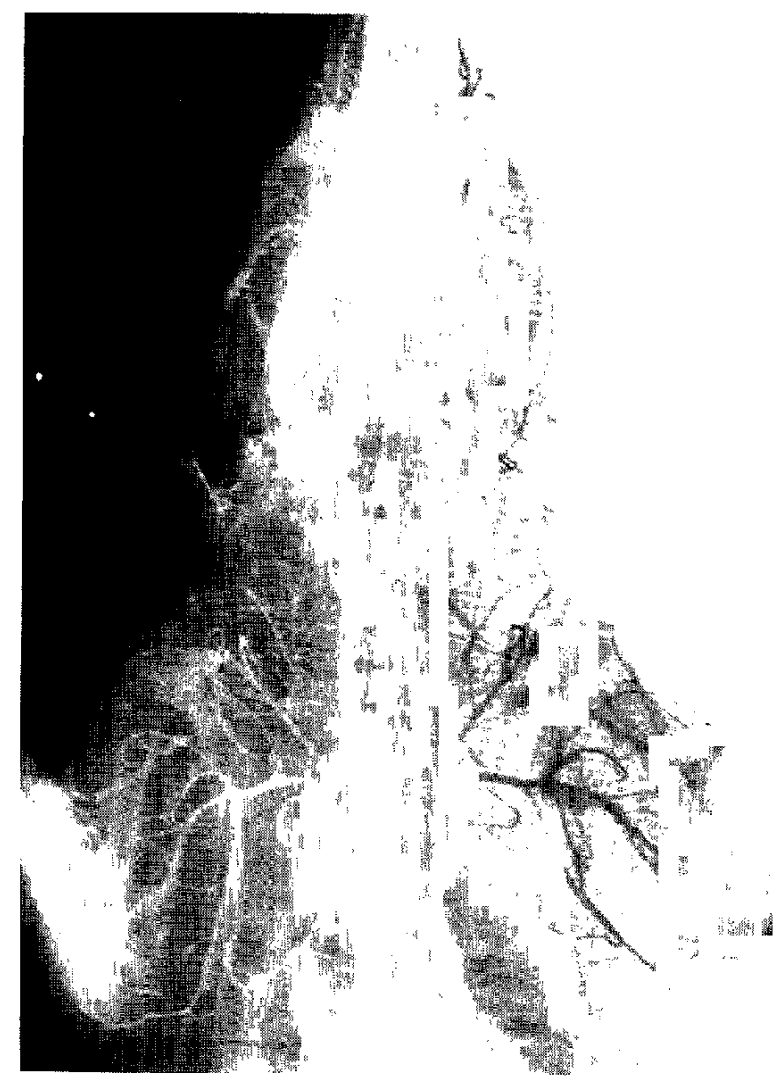

Fig. 2 Angiogram in a rat 1 month after operation. The diameter of the anastomosis was twice the vessel diameter and the anterior wall was closed in running sutures (Group 1-B).

状態を調べ，組織学的検討を行った。また，一部のラット では血管写 ${ }^{17}$ を行った(Fig. 2).

\section{2. 結果}

Table 1 に結果在示す. 第 1 群において術直後の開存 は，吻合口が血管径と同じ大きさのA群全例で保たれた が，2 倍の大きさの B 群では 2 例で閉塞をみた。このうち の 1 例では後壁の mal-adaptationにより declamp 後出向が 多量にあり，組織所見より血栓が吻合部より発生したのち に管内一進展したと思われた。また，他の 1 例では血管の 构じれが原因と思われた。吻合口が血管径の 3 倍の C 群 では 1 例で閉塞がみられ，これは総頸動脈の虽離が少な く，吻合血管の tension が高すぎ，気管に压迫される形で 閉塞したと判断された。これら閉塞をきたしたラットは, その原因を满べるため術直後に sacrifice し，以後の娭討か らは除外している。術直後の肉眠的㹨窄は A, B 群に冬 1 例みられこれれ性手技上の問題(縫いしろの幅など)による と思放たた。 朴梢総頸動脈の血流量の左右差は A 
Tablc 1 Results of side-to-side anastomosis

\begin{tabular}{|c|c|c|c|c|c|c|c|c|}
\hline Group* & Sub-group & $\begin{array}{l}\text { Number } \\
\text { of rats }\end{array}$ & $\begin{array}{l}\text { Size of anastomosis } \\
\text { (of vessel diameter) }\end{array}$ & $\begin{array}{l}\text { Immediate } \\
\text { patency rate }\end{array}$ & $\begin{array}{l}\text { Occlusion } \\
\text { time (min.) }\end{array}$ & Stenosis & $\begin{array}{c}\text { Flow } \\
\text { laterality }\end{array}$ & $\begin{array}{l}\text { Long } \\
\text { survival }\end{array}$ \\
\hline \multirow[t]{3}{*}{1} & A & 4 & $\times 1$ & $4 / 4$ & 17 & $1 / 4$ & $2 / 4$ & $2 / 4$ \\
\hline & B & 7 & $\times 2$ & $5 / 7$ & 18 & $1 / 5$ & $0 / 5$ & $4 / 5$ \\
\hline & $\mathrm{C}$ & 4 & $\times 3$ & $3 / 4$ & 21 & $0 / 3$ & $0 / 3$ & $0 / 3$ \\
\hline 2 & & $10^{* * *}$ & $\times 2$ & $7 / 7$ & 27 & $0 / 7$ & $1 / 7$ & $5 / 7$ \\
\hline
\end{tabular}

${ }^{*}$ Group 1: running sutures, 2: interrupted sutures. ${ }^{* *}$ Rats with obstruction of the anastomosis were eliminated from the later evaluations.

${ }^{* * *}$ Three rats died during the surgery.

群の 2 例にみられ，狭窄および小さすぎる吻合口が原因と 思加た。総頸動脈の血流遮断時間はA 群で头均17分, $\mathrm{B}$ 群で18分，C 群で21分であった。手術侵襲は比較的大き く，頸部諸矨群を大きく損傷するため，また吻合部が気管 を王迫寸るため，術後完全に覚醒したのちも下㖽呼吸，呼 吸困難などを伴いやすく，これが原因で A 群で 2 例， B 群で 1 例，C 群で注全例が数時間から 1 週間以内に死亡し た。これは，吻合口が大きくなるほど手術侵壟が大きくな り，気管への非迫む強くなるためと判断された。以上 り，第 1 群の実験の結論として，吻合口が血管径と同じで は狭窄，末梢血流の左右差を生じやすく，また 3 倍以上で は手術侵襲が大きすぎ，このラットのモデルでは 2 倍が至 適と判断された。

前壁に結節縫合を行った第 2 群においては, 総頙動脈の 血流惑断時閒は前壁在連続縫合した場合に比して長く，平 均27分かかり，このた圽合中に 3 例が死しした。他の 7 例では直後の開存率は $100 \%$ で，肉眼的㹨窄も認められな

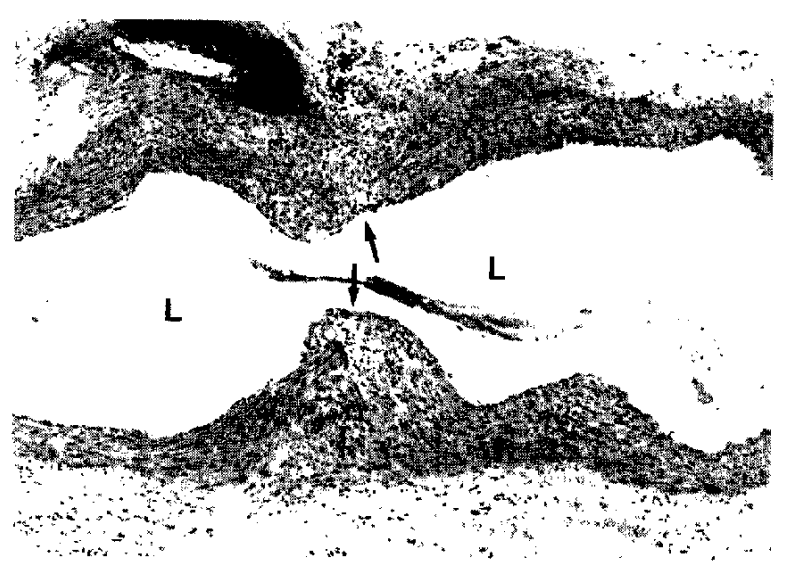

Fig. 3 Photomicrograph of the transected anastomotic orifice 2 months after operation. L shows two vascular lumens, and arrows indicate anastomotic site. Group 2, $\mathrm{HE}$ stain, $\times 40$.
かったが，1例で血流の左右差が認められた，侍期生存率 も7例中 5 例と比挍的良加った。

組織学的所見は第 1,2 群よもほぼ同様で, 軽度内膜肥 厚，時に中膜への細胞浸潤などが認められるのみであった (Fig. 3).

以上より，側々昒含を行う場合，吻合口の大きさは血管 径の 2 倍以上とすべきで，前壁は結節縫合することが必要 であると結論された。

\section{III 臨床応用例}

\section{$<$ 症例 $1>$}

右下肢単森瘏をきたした50才男性で，左前大脳動脈の $\mathrm{A}_{2}$ 部での閉塞がみられた(Fig. 4A, B )。保存的治療にも かかわらず再度虚血発作を生じたため，発证 2 力後に兴 梁周囲動脈の前半で左石学側々吻合した，術中，左 $A_{4}$ 部 でも閉塞がみられ，後脳梁周楝動脈からの側副血行がみら れなかった、CT上前大脳動脈領域に梗塞紧がみられなか ったので術直後より右下肢の麻痺は完全に消失し，血管写 上も吻合部を介して末梢への泉好な血流がみられた(Fig， $4 \mathrm{C}, \mathrm{D})$.

\section{$<$ 症例 $2>$}

右内頸動脈閉塞症をきたした52才男性である，右 STA-


したが，左下肢の中等度の麻瘏は改善をみなかった。血管 写上む前交通動脈を介した左却からの血流が不十分で， またSTA-MCA 吻合からも血流は前大脳動质までは到達 しておらず，右前大脳動脈領域の造影不良が認められた。 このため，発症より 9 力月後に〈症例 1〉と同様な手術を posterior internal frontal artery間で行った(Fig. 5A)。術直 後より下肢の麻痐は改善したが，CT上すでに左下肢に相 当寸る運動領野に梗塞巣がみられていたため麻㾇の改善は 完全ではなかった，血管写では十分な血流が吻合部を介し て右前大脳動脈にみられた(Fig. 5B).

なおこの2 例は他誌にすでに報告したるのである゙． 


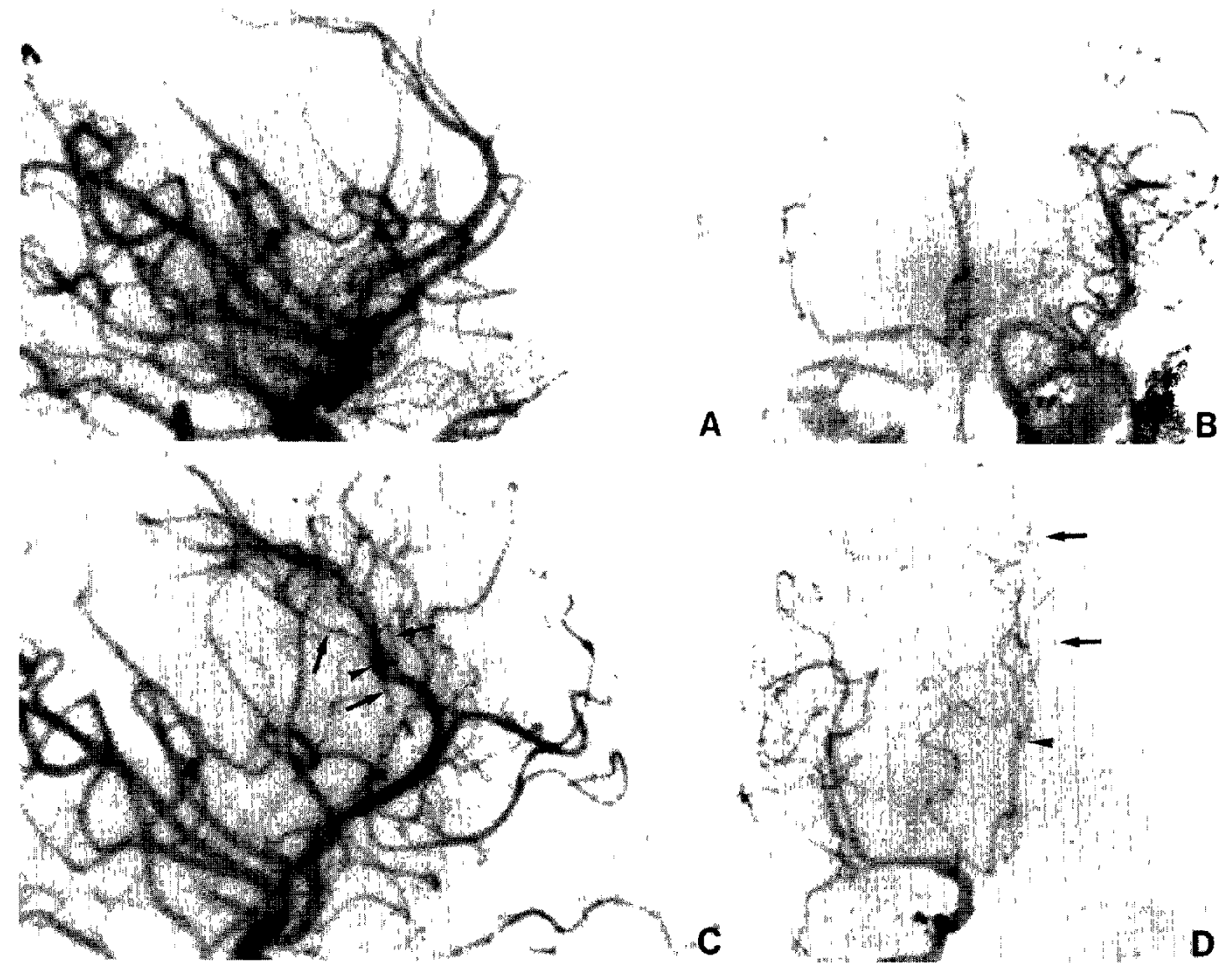

Fig 4 Case 1. A, B Preoperative carotid angiograms on right (A) and on left (B), showing no opacification of the left anterior cerebral artery (ACA) C, D: Postoperatıve right carotıd angıograms showing revascularızed ACA (arrows) and anastomotic orifice (arrowhead)
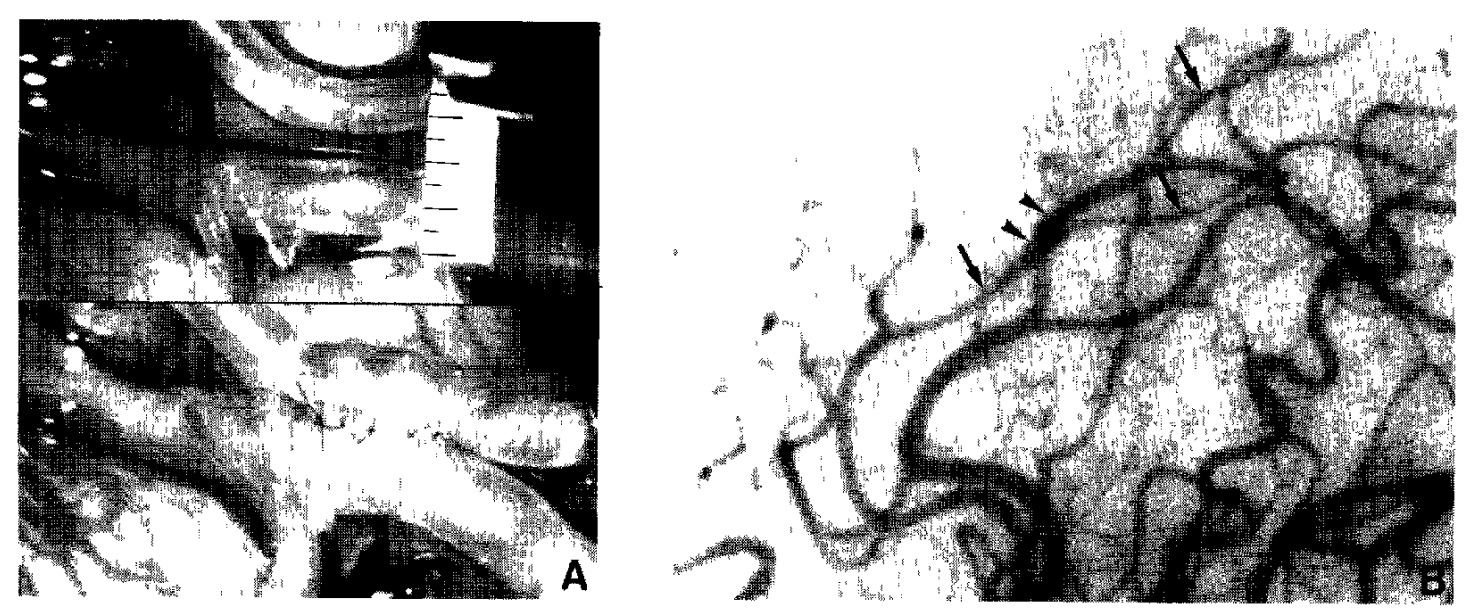

Fig 5 Case 2 A Operative view Note that the artery on the occluded side before the anastomosis (upper) has become larger after the anastomosis (lower). The scalc indicates $05 \mathrm{~mm}$ intervals B Lateral view of postoperative left carotid angiogram showing revascularized ACA (arrows) and the anastomotic site (arrowheads) 


\section{IV 考察}

Yasargil $^{18)}$ により microrevascularizationの千技が脳神経 外科領域に道入されて以来，脳虚血に対して数多くの手術 手技が開発さ扎てきた1,7,10-15!。 しかし，その多くは endto-sideにつなぐ方法で，これらでは開存率を上げるため の基礎的检討むなされてきだ,8,9,16;が， side-to-sideに吻合 寸る試みは非常に少ない2,4,6,13)。

前大脳動脈領域の脸虚血に対する血行再建は, Yasargil ${ }^{18)}$ が試みたのち2,3の報告4-6!があるのみである。 Ishii $ら^{5 /}$ は vein graft 角いてSTAから bypass 行い，

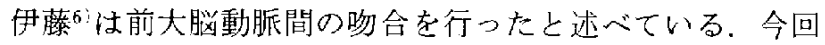
我々は前大脳動脈が $\mathrm{A}_{2}$ 部で閉塞した症例を経験し，血行 再建のう法として伊藤の门方法を用いることにしたが，側 々吻合起行う場合の吻合口の大きさ，縫合方法などの基礎 的な最適条件はまだ判っておらず，今回の奏騃を行った。 またこのモデルは奏際の手術の練習台となりえることも 証明した。

今回，吻合口の大きさを種々に変えた第 1 群の結果，吻 合口の大きさが血管径と可じ場合は吻合部に狭窄が起こり やすく，開存率も低い傾问にあった。また，狭窄がなくて も吻合口を介しての血流が十分でなく，末梢総頸動脈の血 流に左右差を生じる例がみられた。一方，吻合口の大きさ を血管径の 2 倍以上とした埸合，狭窄は起こりにくく，開 存率も高く，また吻合部を介して血流遮断側へも非遮断側 と同量の血流がみられた，以上の点から吻合口の大きさは 血管径の 2 答以上七寸心゙きであるが，3倍とさらに大きく な机吻合に装する時間が長くなり，侵龍も大きくなり， このため失われるラットもみられた。また，長い距離を正 中に寄せると吻合部の tension も大きくなり，閉塞をきた しやすい. ラットのモデルでは 2 倍が至適な大きさと思わ れた。臨床例においても，〈症例 1，2〉ともに血管径の太さ の約 2 倍の大きさの吻合口を設けたが，血管写上十分な血 流が障害側の末梢・中枢側にみられた(Fig. 4, 5).

今回の奏験モデルにおいて，吻合口の後壁は血管内空側 より連続縫合を行った、これは，衁管をクリップごと翻転 させることが今可のラットの実験においてもヒトの削大㨫 動脈間においても不可能であるためである．血管内膜を掑 子でつかまないこと，执よび内腔側に血管壁がまくれ込ま ないことに注意すれば特に閣題はないが，途中でやり直し がきかないため，禾のからまり(これを予防するためには 縫合忞を短くすることが望ましい)や摃子，持針器による 縫合系の damageにも留意が必要である.

さて，前壁の縫合であるが，連続縫合を行うとTable 1 のように血流㵂断時間を短縮できる長所がある。しかし，

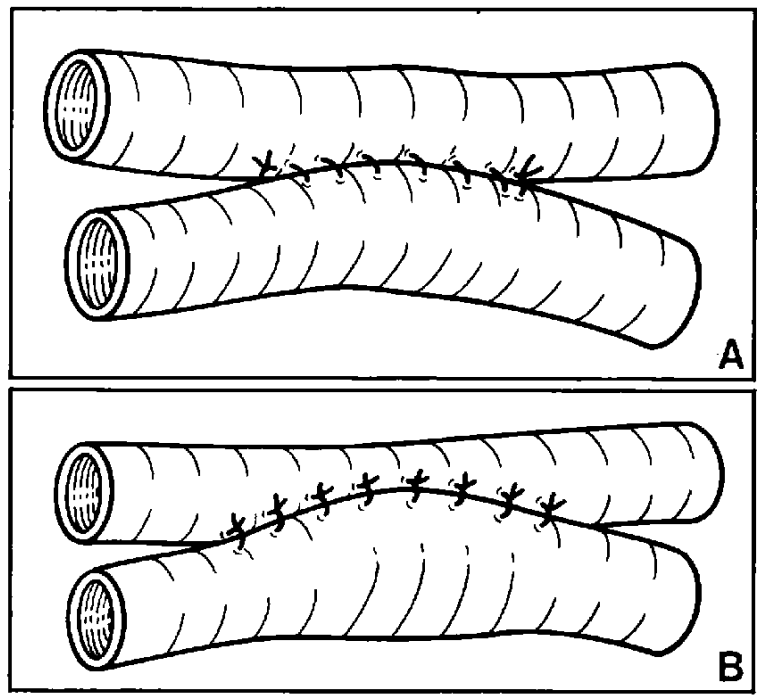

Fig. 6 Comparison of suturing techniques. Anterior wall is sutured in running fashion in Group 1 ( $A$ ), and in interrupted fashion in Group 2 (B). Note that the anterior wall is bulging and that the anastomotic orifice is larger in the vessels with interrupted sutures.

狭窄の有無，木梢血流の左右差，長期生存率など，結節縫 合群のほうが良好な結果が得られた。これは，一つには手 術に熟達し，手技む向上しているためと考えられている が，最大の理由はFig. 6 に示すように吻合後の吻合口の 形状にあると思われる，才なわち，結節縫合を行うと血流 再開後吻合口前壁汢手前に盛り上がり，上り広い吻合口が 得られ，左右の交通が多くなるためと判断された。前壁に 結節縫合を行った臨床例 2 例においても術後の血管写側面 像で吻合部に fusiform 状の拡张が少られ，動物実娩の結 果と一致した。

結節縫合を行う場合，系と系との間隔は密なほうが良 〈9)，微小血管縫合に関して重要な点である血管の approximationをしっかり行い9，また血管壁の重なりを避ける ことが大切である16!。微小血管吻合汇関する他の重要な点 は血管および吻合部の tensionを高くしないことであ $\eta^{16)}$ ここのため今回の奏験においては総頸動脈を上下方向 に可及的に長く剥離しておく必要があった，今回の実験で は，この䟝離が不十分であったことによると思わ扎る閉塞 が1例にみられた。な拉，我々は臨床例に招いても連続。 結節縫合ともに 10-0 monofilament nylon 系を用いたが， Peerless $ら^{8 /}$ は連続縫合の場合，より組織をすべりやすい Prolene 系を使用寸べきとしている，しかし，nylonのほ うが締まりや寸く，扱いも簡単であり ${ }^{16)}$ ，使用に当っては 慣れた系を用いるのがよいと思われる。 


\section{V 結 語}

ラット総頸動脈において側々吻合のモデルを作製し，い かなる条件で開存率が良く，末梢への血流が最大となるか を調べた、結論として，吻合口の大きさは血管径の 2 倍以 上とす心゙きで，斾壁の雄合は結節縫合を用いるべきとの 2 点が得られた。 また，側々吻合の嚚床応用として前大脳動 脈間吻合老施行した 2 症例も併せて示した。

\section{文献}

1) Ausman JI, Diaz FG, De Los Reyes RA, Pak H, Patel S, Mehta B, Boulos R: Posterior circulation revascularization: Superficial temporal artery to superior cerebellar artery anastomosis. J Neurosurg 56: 766-776, 1982

2) Ausman JI, Dujovny M, Mora EO, Umansky F, Diaz FG: Microsurgical reconstruction of the middle cerebral artery, in Spetzler RF, Carter LP, Sclman WR, Martin NA (eds): Cerebral Revascularization for Stroke. New York, Thiem-Stratton, 1985, pp 344-347

3) Eisenhardt HJ, Hennecken H, Klein PJ, Pichlmaier H: Experiences with different techniques of microvascular anastomosis. J Microsurg 1: 341-350, 1980

4) Ikeda A, Okada T, Shibuya M, Noda S, Sugiura M, Iguchi I, Gonda $T$, Kageyama N: Revascularization of the anterior cerebral artery: Report of two cases. J Neurosurg 62: 603-606, 1985

5) Ishii R, Koike T, Takeuchi S, Ohsugi S, Tanaka R, Konno K: Anastomosis of the superficial temporal artery to the distal anterior cerebral artery with interposed cephalic vein graft: Case report. $J$ Neurasurg 58: 425-429, 1983

6）伊藤善太郎：前大脳動脈間吻合術の閉発とをの適応. Neurol Med Chir (Tokyo) 21: 931-939, 1981

7) Little JR, Furlan AJ, Bryerton B: Short vein grafts for cerebral revascularization. J Neurosurg 59: 384-388, 1983
8) Peerless SJ, Gamache FW, Hunter IG: Continuous suture method for microvascular anastomosis: Technical note. Newrosurgery 8: 695-698, 1981

9) Robertson JH, Robertson JT: The relationship between suture number and quality of anastomosis in microvascular procedures. Surg Neurol 10: 241-246, 1978

10) Spetzler RF, Chater N: Occipital artery-middle cercbral artery anastomosis for cerebral artery occlusive disease. Surg Neurol 2: 235-238, 1974

11) Spetzler RF, Rhodes RS, Roski RA, Likavec MJ: Subclavian to middle cerebral artery saphenous vein bypass graft. $J$ Neurosurg 53: 465-469, 1980

12) Story JL, Brown WE Jr, Eidelberg E, Arom KV, Stewart JR Cerebral revascularization: Common carotid to distal middle cerebral artery bypass. Neurosurgery 2: 131-134, 1978

13) Sundt TM Jr, Campbell JK, Houser OW: Transpositions and anastomosis between the posterior cerebral and superior cerebellar arteries: Report of two cases. J Neurosurg 55: 967-970, 1981

14) Sundt TM Jr, Piepgras DG: Occipital to posterior inferior cerebellar artery bypass surgery. $J$ Neurosurg 48: 916-928, 1978

15) Sundt TM Jr, Piepgras DG, Houser OW, Campbell JK: Interposition saphenous vein grafts for advanced occlusive disease and large aneurysms in the posterior circulation. J Neurosurg 56: 205215,1982

16) Tsitsopoulos P, Malbouisson AMB, Harrison MJG: End-toside vascular anastomosis: A study of technical considerations in the rat. $J$ Neurosurg 56: 642-645, 1982

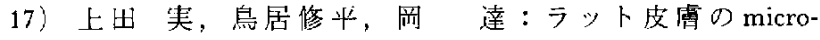
angiography の手技。形成外科 23:627-633，1980

18) Yasargil MG: Microsurgery Applied to Neurosurgery. Stuttgart, Georg Thieme, 1969, pp 95-118

〔別别請求先：可259-11 神奈川県伊勢原市望星台, 東海大学脸 神経外科, 池田 公] 